\title{
Inmigración, integración y diversidad: Un análisis crítico a partir del tratamiento de la mutilación genital femenina en la Unión Europea*
}

\author{
Immigration, Integration and Diversity: \\ A Critical Analysis Based on the Treatment \\ of Female Genital Mutilation in the European Union
}

Julia Ropero Carrasco

Profesora Titular de Derecho Penal

Universidad Rey Juan Carlos

julia.ropero@urjc.es

doi: http://dx.doi.org/10.18543/ced-57-2017pp133-165

Sumario: I. Propuesta de partida: el dilema de la intervención penal ante la MGF en los países occidentales. - II. La MGF como una práctica «aberrante» y el derecho penal cómo respuesta básica: ¿hay cabida para la integración? 1. Planteamiento. El ejemplo de España. 2. Condena penal, repudia social y marginación. 3. Respuesta penal, protección de las menores y derecho a la reagrupación familiar. 4. Recapitulación y propuestas parciales: el Derecho penal como parte de una respuesta social guiada por el principio de integración.-III. Jurisdicción internacional, asilo y refugio en los supuestos de MGF. Algunas contradicciones. - IV. Conclusiones: por una política decidida en la Unión Europea contra la violencia de género y la MGF.-V. Bibliografía.

Resumen: La mutilación genital femenina representa una grave violación de derechos humanos, tal y como recoge el Derecho Internacional más actual. Esta circunstancia y la extensión de la práctica a nivel mundial exigen la intervención del Derecho penal y la toma en consideración de la aplicación del principio de universalidad en su persecución. Sin embargo, la aplicación del Derecho penal en los países de destino a los migrantes, padres de las menores mutiladas, genera un conjunto de dilemas que han de ser abordados no sólo desde una perspectiva humanitaria, sino en aras de una mayor legitimidad en la intervención. En esta búsqueda es preciso reflexionar sobre la falta de un consenso en el ámbito de la Unión Europea sobre estándares referidos a la violencia de género, de la que la MGF es una modalidad, la condición de refugiado y la efectividad del principio de universalidad.

* El presente estudio se enmarca dentro de la Red de Excelencia sobre «Los actuales desafíos del Derecho Internacional», del Plan Estatal de Investigación Científica y Técnica y de Innovación 2013-2016 (DER15-69273-RED). 
Palabras clave: Mutilación genital femenina, violencia de género, diversidad e integración, intervención penal, Derecho Internacional Público y Unión Europea.

Abstract: Female genital mutilation represents a serious violation of the Human Rights as indicated in current International Law. This circumstance and the world-wide spread of the practice require a Criminal Law intervention and the consideration of applying the Principle of Universality in its prosecution. However, the application of Criminal Law in the destination countries to those migrants who are the parents of the mutilated minors produces a set of dilemmas which must be addressed. This must happen from a humanitarian perspective whilst upholding a higher legitimacy in the intervention. In this research effort it is essential to reflect on the lack of agreement in the European Union about standards referring to gender violence, of which FGM is a typology, the condition of refugee and the effectiveness of the Principle of Universality.

Keywords: Female genital mutilation, gender violence, diversity and integration, Criminal Law intervention, Public International Law and European Union.

\section{Propuesta de partida: el dilema de la intervención penal ante la mutilación genital femenina (MGF) en los países occidentales}

Según la Organización Mundial de la Salud (OMS), la mutilación genital femenina (MGF) abarca todos los procedimientos consistentes en la ablación parcial o total de los órganos genitales femeninos externos o cualquier daño a los genitales femeninos, causados por razones culturales u otras y no con fines terapéuticos. Se diferencian cuatro tipos principales ${ }^{1}$ :

${ }^{1}$ Organización Mundial para la Salud. «Mutilación genital femenina. Nota descriptiva», febrero, 2016. Entrada el 30 de noviembre de 2016.

http://www.who.int/mediacentre/factsheets/fs241/es/. Sobre los diferentes tipos de mutilación genital femenina y sus secuelas, cfr. también, Protocolo común para la actuación sanitaria ante la Mutilación Genital Femenina (MGF), Ministerio de Sanidad, Servicios Sociales e Igualdad, Gobierno de España (2015): 21-28. Disponible en:

http://www.msssi.gob.es/organizacion/sns/planCalidadSNS/introProtocoloComun2015. htm. «Mutilatations Génitales Féminines: Guide à l'usage des professions concernées». SPF Santé publique, Sécurité de la Chaîre alimentaire et Environnement et GAMS Belgique. Bruxelles (2011). Disponible en:

http://www .endfgm.eu/resources/tools-and-training-resources/mutilations-gnitalesfminines-guide-lusage-des-professions-concernes-2011/. Adriana Kaplan Marcusán y Cristina Martínez Bueno (coords.). «Mutilación genital femenina: prevención y atención. Guía para profesionales», Associació Catalana de Llevadoras, Barcelona (2004): 9-19. 
- Tipo I o Clitoridectomía: resección parcial o total del clítoris (y en algunos casos, sólo del prepucio a capuchón del clítoris).

- Tipo II o Escisión: recesión parcial o total del clítoris y los labios menores (con o sin escisión de los labios mayores).

- Tipo III o Infibulación: estrechamiento de la abertura vaginal para crear un sello mediante el corte y recolocación de los labios menores o mayores, con o sin resección del clítoris.

- Tipo IV: amplio abanico de prácticas variadas e inclasificables. Procedimientos lesivos de los genitales externos con fines no médicos: perforación, incisión, raspado, cauterización.

En la mayoría de estos casos la mutilación genital representa una importante lesión contra la integridad física. Sin embargo, las consecuencias van más allá: por un lado, la forma en la que muchas de estas mutilaciones se realizan puede determinar que en el momento de la intervención, ya sea por la pérdida de sangre, por el choque producido por el dolor o por la infección (a través de una septicemia), se cause la muerte. A corto plazo, la mutilación genera hemorragias capaces de crear daños diversos, así como tumores, problemas de retención de orina o lesiones en los tejidos circundantes, entre otros. A largo plazo, es frecuente que las mutiladas padezcan toda su vida dolores en la zona, creados por quistes en la piel, así como infecciones graves en los órganos genitales (debido a las dificultades para expulsar el flujo menstrual) o diversas secuelas en el tracto urinario (infecciones crónicas, piedras y otros trastornos renales) ${ }^{2}$.

Junto a estas secuelas de carácter físico hay que mencionar el atentado contra la integridad moral, así como las negativas repercusiones que esta intervención provoca en el libre desarrollo y disfrute de la sexualidad de estas mujeres. En las formas más agresivas de mutilación, la primera relación sexual se convierte en una experiencia sumamente dolorosa, que requiere una intervención previa para abrir los labios y el acceso a la vagina. La escisión total o parcial del clítoris representa un obstáculo en ocasiones insalvable para el disfrute sexual. A todo ello hay que unir los evidentes proble-

http://www.aen.es/docs/guias_vg/guia_mutilacion_genital.pdf.

UNICEF. «United Nations Children'Fund, Female Genital Mutilation/Cutting: A global concern», New York, 2016. Acceso el 30 de noviembre de 2016.

https://www.unicef.org/media/files/FGMC_2016_brochure_final_UNICEF_SPREAD.pdf.

Female genital mutilation in the European Union and Croatia. European Institute for Gender Equality, 2013.

http://eige.europa.eu/sites/default/files/documents/eige-report-fgm-in-the-eu-and-croatia.pdf

2 Julia Ropero Carrasco, «La mutilación genital femenina: una lesión de los derechos fundamentales de las niñas basada en razones de discriminación sexual», en Cursos de Derechos humanos de Donostia-San Sebastián, Vol. 4, ed. por Juan Soroeta Liceras (San Sebastián: Universidad del País Vasco, 2003), 357-360. 
mas psicológicos creados por el trauma derivado de la propia intervención, la ansiedad crónica asociada a cualquier actividad relacionada con la zona genital o el miedo a la infertilidad (pues los informes médicos ponen de manifiesto que la mutilación, debido a los trastornos que provoca -infecciones, quistes - se presenta como una importante causa de infecundidad) ${ }^{3}$.

La intervención del Derecho penal en la lucha contra la MGF es irrenunciable. Las mutilaciones genitales constituyen un grave atentado contra bienes jurídicos fundamentales, como son la integridad física y, en una concepción más amplia, la salud (incluyendo la salud psíquica, el bienestar físico y el pleno disfrute de la sexualidad y de la maternidad). La amenaza de la pena resulta un medio necesario para que se extienda la convicción (de forma específica, entre las comunidades en las que la MGF está arraigada) de que las mutilaciones representan una forma de lesión grave sin que el carácter de costumbre cultural que se adjudica a estas prácticas pueda justificarlas. La protección de los bienes jurídicos y de los derechos fundamentales por encima de cualquier práctica consuetudinaria (por mucho que se considere una manifestación cultural) aparece recogida en numerosas normas de Derecho Internacional. La Declaración de NU sobre la Eliminación de la Violencia contra la Mujer, de 1993, estableció en su artículo 4 que los Estados no deben invocar ninguna costumbre, tradición o consideración religiosa para eludir su obligación de eliminar la violencia contra la mujer. Después, otros instrumentos internacionales, a nivel mundial o regional (especialmente Unión Europea y Consejo de Europa), consolidaron este principio, como más adelante se detalla.

Ahora bien, admitido esto, es necesario advertir que la intervención del Derecho penal como mecanismo de respuesta y de prevención frente a la MGF acarrea numerosos problemas que todavía hoy no han sido satisfactoriamente resueltos, siendo necesario diferenciar entre los planteados en los países de origen de la práctica y los suscitados en los de destino de los migrantes. En las regiones del mundo donde la MGF se encuentra más extendida, Egipto y África Subsahariana, la dificultad más significativa a la que hacer frente es la falta de eficacia del Derecho Penal: a pesar de que muchos de estos países, ante la presión internacional, han prohibido expresamente las mutilaciones, en la práctica estos hechos no se persiguen por distintas razones. En algunos casos, es la falta de medios para hacer frente a una política de prevención necesaria para garantizar la efectividad de la prohibición; en otros, la debilidad de las estructuras del Estado o la corrupción abonan el desinterés por un tema que no resulta prioritario; en la mayoría, a todos estos factores se suman las dificultades de carácter social y

3 Véanse los documentos citados en nota 1. 
cultural para transformar tradiciones arraigadas en las estructuras tribales, en las que el individuo tiene un valor relativo frente al poder de la comunidad. La ineficacia del Derecho Penal en los países de origen conduce a la consolidación de la práctica en los mismos, al extenderse la creencia de que al margen de lo dispuesto en las leyes existen otras normas morales, sociales o culturales que tienen prevalencia.

La convicción acompaña a los migrantes hasta el mundo occidental, y funda la pretensión de ostentar un derecho a una identidad cultural mediante la conservación de las propias tradiciones. Al igual que ocurre con otras prácticas (como puede ser el ayuno en Ramadán, o vestir el velo, por ejemplo) el desarraigo y la vulnerabilidad de los inmigrantes impulsan la necesidad de reafirmar dicha identidad para fortalecer su dignidad como persona. Sin embargo, el choque entre esta pretensión y la realidad de los países de destino es mucho más dramático cuando hablamos de mutilación genital femenina: el vestido del velo en los países occidentales puede ser más o menos admitido; la mutilación genital es una práctica que repugna a la sociedad, y el sentimiento de desaprobación, enfatizado por el etiquetamiento que representa la intervención penal, envuelve no sólo a las víctimas más directas, las niñas mutiladas o en riesgo de serlo, sino también a sus padres y familiares.

\section{La MGF como una práctica «aberrante» y el derecho penal cómo respuesta básica: ¿hay cabida para la integración?}

\section{Planteamiento. El ejemplo de España}

A finales de los años 90 del siglo pasado se detectaron en España los primeros casos de MGF en niñas y mujeres inmigrantes procedentes de países del África subsahariana, residentes en diversas zonas de Cataluña, Baleares y Aragón. Tras ello se inició un debate en el que predominó una línea político criminal represiva reclamándose dos medidas: por un lado, la tipificación expresa en el Código penal (CP en lo que sigue) del delito de mutilación genital femenina, lo que requería una reforma de los tipos de lesiones, y por otro la modificación del artículo 23. 4 de la Ley Orgánica del Poder Judicial (en adelante LOPJ), en el sentido de incluir a la MGF dentro de la lista de delitos que, de acuerdo con el principio de universalidad o de justicia mundial, pueden ser perseguidos por los Tribunales españoles ${ }^{4}$.

${ }^{4}$ Sobre este proceso, cfr. Julia Ropero Carrasco, «El Derecho Penal ante la Mutilación genital femenina», La Ley, n.6 (2001): 1393-1395. 
En respuesta a estas demandas, la LO 11/2003, de 29 de septiembre, de medidas concretas en materia de seguridad ciudadana, violencia doméstica e integración social de los extranjeros ${ }^{5}$, introdujo un nuevo apartado en el artículo 149 , referido a las lesiones graves, con el siguiente texto:

Art. 149. (...) 2. «El que causara a otro una mutilación genital en cualquiera de sus manifestaciones será castigado con la pena de prisión de seis a doce años. Si la víctima fuera menor o incapaz ${ }^{6}$, será aplicable la pena de inhabilitación especial para el ejercicio de la patria potestad, tutela, curatela, guarda o acogimiento por tiempo de cuatro a diez años, si el juez lo estima adecuado al interés del menor o incapaz.

En la Exposición de Motivos de la mencionada LO 11/2003 se explicaba que:

«(...) la reforma se plantea desde el reconocimiento de que con la integración social de los extranjeros en España aparecen nuevas realidades a las que el ordenamiento debe dar adecuada respuesta. Así, como novedad igualmente reseñable se tipifica el delito de mutilación genital o ablación. Y ello porque la mutilación genital de las mujeres y niñas es una práctica que debe combatirse con la máxima firmeza, sin que pueda en absoluto justificarse por razones pretendidamente religiosas o culturales. (...) En la actual reforma se modifica el artículo 149 del Código penal, mencionando expresamente en su nuevo apartado 2 la mutilación genital, en cualquiera de sus manifestaciones, como una conducta encuadrable entre las lesiones de dicho artículo, castigadas con prisión de seis a doce años. Se prevé, además, que si la víctima fuera menor de edad o incapaz, se aplicará la pena de inhabilitación especial para el ejercicio de la patria potestad, si el juez lo estima adecuado al interés del menor. En la mayoría de las ocasiones son los padres o familiares directos de la víctima quienes la obligan a someterse a este tipo de mutilaciones aberrantes, por lo cual la inhabilitación especial resulta absolutamente necesaria para combatir estas conductas y proteger a la niña de futuras agresiones o vejaciones».

5 BOE n. ${ }^{\circ} 234$, de 30 de septiembre de 2003.

${ }^{6}$ El término «incapaz» fue sustituido por el de «persona con discapacidad necesitada de especial protección» por la LO 1/2015, de 30 de marzo (BOE n. ${ }^{\circ} 77$, de 31 de marzo), con entrada en vigor el 1 de julio de 2015.

7 También sustituido por «persona con discapacidad necesitada de especial protección». 
A pesar de que le Ley se refiere a la «integración social de los extranjeros», tanto de la nueva regulación del artículo 149 como del extracto de la Exposición de Motivos se deduce sin lugar a dudas que el concepto de «integración» manejado por el legislador penal está muy alejado del principio de reconocimiento de la diversidad que preside las teorías de la multiculturalidad o interculturalidad en las sociedades contemporáneas. Con ello no quiere decirse que el Derecho penal no deba intervenir en este ámbito o que las lesiones derivadas de la MGF estén justificadas por razones culturales. Tan sólo se pretende enfatizar que la respuesta penal debería estar justificada más bien en la necesidad de salvaguardar los bienes jurídicos afectados, aunque de forma mediata la intervención de los Tribunales produzca un efecto estigmatizador que precisamente dificulta la integración. El énfasis en la responsabilidad de los padres y la medida de la inhabilitación para la patria potestad, así como una especie de presunción de que en estos casos pueden producirse «futuras agresiones o vejaciones», o la definición de las mutilaciones como «aberrantes», evidencian un acercamiento desde una posición de supremacía moral y de repulsa que parece no detenerse en la penalización de la práctica ${ }^{8}$.

Cabe esperar que la intervención penal consiga su fin esencial que es la prevención, de modo que la tipificación expresa de la MGF contribuya a la intimidación para que estas prácticas sean erradicadas. Pero al lado de este efecto positivo resulta necesario advertir otras posibles consecuencias de la aplicación del Derecho Penal, pues el instrumento del que se vale, la imposición de la pena, no sólo representa la limitación de derechos fundamentales sino que se trata de una medida acompañada de un proceso de marginación social que inevitablemente entorpecerá la integración ${ }^{9}$. Veamos esto más despacio.

\section{Condena penal, repudia social y marginación}

Toda condena penal conlleva una razonable repudia social. Sin embargo, en el ámbito de la MGF cabe esperar que la contextualización de este rechazo sobre criterios de superioridad cultural, e incluso racial, acarree una

${ }^{8}$ Los riesgos de la utilización del Derecho Penal como única respuesta a la MGF, así como de la carga emocional excesiva en la valoración de esta práctica son destacados por Sara Johnsdotter. «The FGM Legislation Implemented: Experiences from Sweden», Cuadernos de Filosofía del Derecho, n. ${ }^{\circ} 17$ (2008): 7-12.

${ }_{9}$ Michela Fusaschi. «Modifications génitales féminines en Europe: raison humanitaire et universalismes ethnocentriques», Synergies Italie, n. ${ }^{\circ} 10$ (2014): 101-102. 
mayor marginación de los colectivos de inmigrantes que incluyen entre sus costumbres la $\mathrm{MGF}^{10}$.

Desde una perspectiva crítica se ha advertido del discurso hegemónico y etnocéntrico existente en torno a la MGF entre los medios de comunicación, que desprecia y estigmatiza las prácticas que provienen del «mundo subdesarrollado» sin advertir que en la sociedad occidental pueden existir otras similares. Bajo este enfoque, destaca Isabel Ortega, Occidente aparece como el procurador de la libertad y la integridad, despreciando la existencia de la lucha contra la MGF llevada a cabo por las mujeres africanas ${ }^{11}$. De manera expresa, Maria Caterina La Barbera duda de que las leyes penales representen el instrumento más adecuado para resolver los conflictos interculturales, denunciando su ineficacia y la posible potenciación del efecto contrario: la reafirmación de las prácticas; por ello, reclama que sean otros sectores del Ordenamiento y otras disciplinas las que den respuestas a la MGF'12.

Aun admitiendo la necesidad de la intervención penal, la mayoría de los autores subraya el dilema ético que representa asumir esta respuesta como la primera e inmediata en los países de destino de los inmigrantes: el riesgo de ser procesada se cierne sobre la mujer africana desde el primer momento que llega a un país occidental, proveniente de una sociedad en la que la práctica de la MGF le es impuesta: en sus países de origen las mujeres se convierten en las víctimas de la mutilación y al mismo tiempo se erigen en las garantes de su perpetración sobre sus propias hijas. La inmigración a países occidentales se lleva a cabo sin tiempo para asumir un cambio tan radical en sus creencias, lo que se traduce en la imposición de un nuevo rol marginal: el de ser declarada culpable por las graves lesiones sufridas por su hija. Como acertadamente se pregunta Adela Asúa, «ipodemos ignorar el condicionamiento cultural que afecta a la persona encausada, sin infringir la máxima que obliga a tratar igual lo igual, y su

10 Advertía de esto Myriam Herrera Moreno, «Multiculturalismo y tutela penal: a propósito de la problemática sobre la mutilación genital femenina». Lex Nova, n. ${ }^{\circ} 5$ (2002): 51-52. También Els Leye y Jessika Deblonde, «A comparative analysis of the different legal approaches towards female genital mutilation in the 15 EU Member States, and the respective judicial outcomes in Belgium, France, Spain, Sweden and the UK», ICRH Publications, n. ${ }^{\circ} 8$ (2004): 44-45.

11 Isabel Ortega Sánchez, «Narrativas periodísticas en torno a la ablación / mutilación genital femenina», en I Congreso Internacional de Educación y Género, ed. por Juan Carlos Suárez Villegas, Irene H. Liberia Vayá, Belén Zurbano-Berenguer (Sevilla: Universidad de Sevilla, 2012),1892-1894.

12 María Caterina La Barbera, «Mujeres, migración y Derecho penal: el trato jurídico de la mutilación genital femenina», Sortuz. Oñati Journal of Emergent Socio-legal Studies, n. ${ }^{\circ} 4$, 1 (2010): 57-60. 
reverso, de forma desigual lo que es desigual? (...) ¿Una mutilación intencional sin otro motivo que el de perjudicar y lesionar a la víctima puede equipararse a una mutilación realizada para cumplir con un rito ancestral, conforme a dictados culturales sentidos como ejercicio responsable para asegurar la inserción de las hijas en la propia comunidad?» ${ }^{13}$. En definitiva, aunque un sector mayoritario acepta la necesidad preventiva de la pena como punto de partida, exige al mismo tiempo un enfoque multidisciplinar y que tenga en cuenta la diversidad cultural y la integración como aspiración esencial de una sociedad democrática, trabajando por ello en la educación y la sensibilización ${ }^{14}$.

Esta demanda es justa y ha de ser compartida. Igualmente hay que conceder a Adriana Kaplan y otros ${ }^{15}$ que los Servicios de Salud y los Servicios Sociales, por «sus características de proximidad, accesibilidad y universalidad, constituyen el espacio idóneo para permitir la aproximación a este reto intercultural que plantean las nuevas ciudadanías en el país». Esta idea es recogida en el «Protocolo común para la actuación sanitaria ante la mutilación genital femenina» ${ }^{16}$ del Ministerio de Sanidad, Servicios Sociales e Igualdad, que entre otros aspectos recomienda un abordaje preventivo basado en la generación de una relación de confianza con los migrantes, que garantice el debido respeto a la persona empleando el tiempo necesario para ello a través de las consultas que sean necesarias ${ }^{17}$.

13 Adela Asua Batarrita, «Criminología y multiculturalismo. Medidas internacionales y propuestas de tratamiento jurídico para la erradicación de la mutilación genital femenina», Eguzkilore, n. ${ }^{\circ} 18$ (2004): 94-96.

${ }^{14}$ De esta opinión Elena Torres Fernández, «La mutilación genital femenina: un delito culturalmente condicionado», Cuadernos Electrónicos de Filosofía del Derecho, n. ${ }^{\circ} 17$ (2008): 18-21; Grande-Gascón, María Luisa; Ruiz-Seisdedos, Susana; Hernández-Padi1la, María. «El abordaje social y político de la mutilación genital femenina». Portularia, Vol. XIII, n. ${ }^{\circ} 1$ (2013): 11-18; Rocío Salamanca de Dueñas, «Dossier II: Mutilación genital femenina: análisis criminológico y tratamiento jurídico penal», Quadernos de criminología: revista de criminología y ciencias forenses, n. ${ }^{\circ} 26$ (2014): 29-30; Nieves Sanz Mulas, «Diversidad cultural y política criminal: estrategias para la lucha contra la mutilación genital femenina en Europa (especial referencia al caso español)», Revista Española de Ciencia Penal y Criminología, 16-11 (2014) 11:45-11:49, http://criminet.ugr.es/recpc/16/ recpc16-11.pdf.

15 Adriana Kaplan, Pere Torán, Kira Bermúdez y María José Castany, «Las mutilaciones genitales femeninas en España: posibilidades de prevención desde los ámbitos de la atención primaria de salud, la educación y los servicios sociales», Revista Migraciones, n. ${ }^{\circ} 19$ (2006): 189-217.

16 Disponible en:

http://www.msssi.gob.es/organizacion/sns/planCalidadSNS/introProtocoloComun2015. htm.

17 Páginas 66-67 del Protocolo. 
Sin embargo, si lo que queremos es evitar la aplicación del Derecho penal con las duras consecuencias que éste arrostra, tal vez no dispongamos de ese tiempo. Como la mutilación genital femenina es un delito, es preciso recordar lo dispuesto en los artículos 262 y 355 de la Ley de Enjuiciamiento Criminal (Lecrim), que recogen la obligación de denuncia impuesta a los profesionales, médicos y personal sanitario, que tengan conocimiento de la comisión del mismo ${ }^{18}$. Siendo esto así, la apreciación de signos de mutilación en las madres representa un riesgo para las niñas menores de cuantificación compleja (la MGF no sólo se lleva a cabo en los viajes a los países de origen). Por esta razón, aunque la atención socio sanitaria propuesta es esencial, deberíamos advertir que además de todo ello se imponen dos actuaciones concretas, a corto y a largo plazo.

A largo plazo, a la actuación socio sanitaria habría que unir una campaña de sensibilización social (en los países de destino) y de educación y formación a distintos niveles, para que al sentimiento de rechazo ante una práctica que se juzga de culturas inferiores, se una el interés en afrontar este problema con la sensibilidad y el humanismo que impone el respeto a la dignidad del otro como un igual. Al mismo tiempo, a corto plazo, sería oportuno desarrollar un programa de intervención más inmediata, que garantizase de la manera más rápida posible el acceso del migrante a la información sobre la penalización de la MGF y de las consecuencias del Derecho Penal. La limitación de los recursos públicos ha repercutido, al menos en España, en que la atención «socio sanitaria» se vea reducida a la «sanitaria» (ésta última también amenazada en su dispensa universal). Por esa razón, conviene potenciar la actuación de los servicios sociales de los Ayuntamientos, auxiliados por las Policías Locales, no en una función represiva o de seguridad, sino de asistencia y prevención, para garantizar el censo de los migrantes y el acceso urgente a la información sobre el control de las prácticas tradicionales lesivas.

Porque la marginación es sin duda una consecuencia indeseable, pero no es la única ni la más grave que se deriva de la aplicación del Derecho Penal, como vemos a continuación.

${ }^{18}$ El artículo 262 de la Lecrim señala:

«Los que por razón de sus cargos, profesiones u oficios tuvieran noticia de algún delito público, estarán obligados a denunciarlo inmediatamente al Ministerio Fiscal, al tribunal competente, al juez de instrucción y, en su defecto, al municipal o al funcionario de policía más próximo al sitio, si se tratase de un delito flagrante».

Por su parte, el artículo 355 dispone:

«Si el hecho criminal que motive la formación de una causa cualquiera consistiese en lesiones, los médicos que asistieran al herido estarán obligados a dar parte de su estado». 


\section{Respuesta penal, protección de las menores y derecho a la reagrupación familiar}

El Protocolo común para la actuación sanitaria ante la Mutilación Genital Femenina ${ }^{19}$, dirigido especialmente al personal sanitario, advierte que la información a las autoridades referida a estas prácticas puede representar la pérdida de confianza de las familias, con la repercusión negativa para la salud. Siendo esto de una importancia innegable, debemos recordar que el artículo 149 CP castiga la mutilación genital con penas de prisión de seis a doce años, que implican el ingreso en la cárcel de los autores del delito sin posibilidad de suspensión de la condena.

La condena de los padres como autores (aunque sea por un delito de omisión debido a su responsabilidad como garantes), deja a las menores en manos de la tutela del Estado, sumándose a su condición de víctima de la mutilación y a su estatus de pertenencia a un colectivo marginal, la situación de vulnerabilidad y revictimización al perder su entorno familiar más inmediato, que pasa a estar criminalizado. En este ámbito, es preciso tener en cuenta la Ley 26/2015, de 28 de julio, de modificación del sistema de protección a la infancia y a la adolescencia ${ }^{20}$, que en su artículo 11 reconoce al mismo tiempo como principios rectores de la acción administrativa la supremacía del interés superior del menor (letra a), el mantenimiento en su familia de origen, salvo que no sea conveniente para su interés (letra b), su integración familiar y social (letra c) y la protección contra toda forma de violencia (...) incluyendo (...) la mutilación genital femenina y cualquier otra forma de abuso (letra i).

De esta ley se deriva claramente que uno de los principios rectores es la protección del menor frente a la mutilación genital femenina, al que responde, entre otras medidas, la tipificación en el CP. Ahora bien, si la mutilación ya se ha producido cuando las niñas llegan a España, o tiene lugar en territorio español y ha sido descubierta y está siendo juzgada, la supremacía del interés superior del menor debería estar presente entre los distintos intereses a considerar, tanto durante el proceso penal, como en la sentencia a imponer y en las condiciones de ejecución de la misma $^{21}$. Advirtiendo, al mismo tiempo, que, en contra de lo que parece presuponer el legislador penal cuando en la Exposición de Motivos de la

19 Disponible en:

http://www.msssi.gob.es/organizacion/sns/planCalidadSNS/introProtocoloComun2015.htm.

20 BOE número 180, de 29 de julio de 2015.

21 Advierte también de los posibles efectos indeseables para los intereses de las menores, Sanz Mulas, «Diversidad cultural y política criminal: estrategias para la lucha contra la mutilación genital femenina en Europa (especial referencia al caso español)», 11:31. 
Ley $11 / 2003^{22}$ se refiere a la inhabilitación especial para la patria potestad como medida a imponer para evitar «futuras agresiones», en los casos de la MGF el peligro de otras agresiones no es un dato a considerar, ya que la mutilación en sí no es siquiera sentida como una agresión, sino como un cumplimiento responsable de una tradición, que no dice nada en sí misma de otras posibles agresiones.

Las consecuencias para las menores derivadas del ingreso en prisión de los padres pueden estar detrás de la corriente mayoritaria en la jurisprudencia que se inclina por la absolución o la atenuación de la pena, alegando bien el desconocimiento de la mutilación ${ }^{23}$ la ausencia de intención de causar lesiones ${ }^{24} \mathrm{o}$ el error sobre la ilicitud de su conducta (ya sea como eximente ${ }^{25}$ o atenuante $\left.{ }^{26}\right)$. Sin embargo, un análisis detenido de las decisiones jurisprudenciales no permite deducir un criterio claro de tratamiento ya que en situaciones bastante similares se ha llegado a soluciones muy diversas, de modo que la alegación del desconocimiento de la situación ha sido reconocida por los Tribunales de manera muy diversa: como circunstancia eximente, como simple atenuante o incluso rechazada de manera explícita, sin que en el relato fáctico se aprecien, insisto, diferencias sustanciales entre los casos juzgados ${ }^{27}$.

${ }^{22}$ Ley 11/2003, de 29 de septiembre (BOE n. ${ }^{\circ} 234$, de 30 de septiembre), de medidas concretas en materia de seguridad ciudadana, violencia doméstica e integración social de los extranjeros.

${ }^{23}$ Cfr. la Sentencia de la Audiencia Nacional (SAN), núm. 36/2012, de 24 de julio, que absuelve al padre de la menor, que había inmigrado en primer lugar a España, invocando su falta de conocimiento de la situación, al ser realizada la mutilación genital de la niña en Senegal.

${ }^{24}$ Cfr. la SAN núm. 5/2014 de 24 de febrero, que absuelve a los padres de la niña mutilada alegando ausencia de dolo de lesionar.

${ }^{25}$ Cfr. la Sentencia del Tribunal Supremo (STS) núm. 939/2013, de 16 de diciembre.

${ }^{26}$ Cfr. la STS núm. 835 de 2012, de 31 de octubre, que castiga a los padres de origen gambiano de una menor mutilada, imponiendo una pena de seis años de prisión al padre, al no considerar la alegación de un error sobre la ilicitud del hecho en la medida en que éste llevaba varios años de residencia en España, y dos años de prisión para la madre, a quien sí se le aplica una atenuante de error de prohibición vencible, hasta llegar a una cantidad que permite la suspensión de la ejecución de las penas previstas en el artículo $80 \mathrm{CP}$, que señala en su número 1:

«Los jueces o tribunales mediante resolución motivada, podrán dejar en suspenso la ejecución de las penas privativas de libertad no superiores a dos años cuando sea razonable esperar que la ejecución de la pena no sea necesaria para evitar la comisión futura por el penado de nuevos delitos (...)».

${ }^{27}$ En la STS núm. 399/2014, de 8 de mayo, el Tribunal Supremo confirma la Sentencia dictada por la Sección Novena de la Audiencia Provincial de Barcelona, de 13 de mayo de 2013, castigando a los padres de origen gambiano por la mutilación genital de su hija menor, a las penas de seis años de prisión para cada uno de ellos, rechazando la petición de atenuación por error de prohibición. 
Un ejemplo que destaca la falta de un criterio certero, y que al mismo tiempo señala el interés final en evitar la cárcel para al menos uno de los progenitores es el caso resuelto finalmente en la STS núm. 939/ 2013 de 16 de diciembre, que contiene los siguientes antecedentes:

El acusado, BT, inmigrante de Senegal, vino a trabajar a Cataluña en 1999, dejando en su país, a su esposa, FD, y a sus dos hijos varones, si bien regresó allí en diversas ocasiones. El 20 de septiembre de 2006, cuando el citado acusado se encontraba trabajando en Cataluña, nació en Senegal su hija A. a quien le practicaron la amputación genital, sin que conste acreditado que tuviera conocimiento de lo sucedido. Una vez que BT consiguió la reagrupación familiar, lo que permitió que su esposa FD y sus tres hijos vinieran a España en el 2010, llevaron a la pequeña A. al Centro de Salud Primaria de Premiá de Mar, donde tras el reconocimiento médico practicado le fue detectada la ausencia de clítoris así como una sinequia o adherencia de labios menores. En los procesos penales que siguieron a estos hechos, la prueba de cargo de mayor peso fue la declaración del enfermero que atendió a la familia, en el sentido de que no hubo reacción de especial sorpresa por parte de los padres. La madre no intervino, ya que no hablaba español, sólo mandinga, y el padre señaló que la ablación sufrida por su hija era un hecho cultural en África y que su esposa también sufrió la misma lesión consecuencia de las costumbres imperantes en las zonas rurales de su país. Denunciados los hechos por el Centro de Salud, el Juzgado Central de Instrucción n. ${ }^{\circ} 5$ instruyó sumario contra los padres en 2011. La madre desapareció y fue declarada en rebeldía el 5 de diciembre de 2011, acordándose su busca y captura. El proceso contra el padre, BT, finalizó con la Sentencia de la Audiencia Nacional de 24 de julio de 2012, que le absolvió del delito de lesiones del artículo 149.2 del Código penal por el que había sido inicialmente acusado, si bien el Ministerio Fiscal retiró la acusación y solicitó una sentencia absolutoria. Uno de los fundamentos jurídicos esgrimidos fue la imposibilidad de constatar que el padre hubiese participado de manera directa en la comisión del hecho. Al mismo tiempo, el Tribunal consideró que el tipo penal sólo tenía sentido para proteger a las menores que se encontraban en situación de riesgo en España, y no a las que habían sido mutiladas en su país de origen. La madre, FD, tras ser capturada fue procesada en la Audiencia Nacional, quien en su sentencia de 4 de abril de 2013, el mismo tribunal que había absuelto al padre, le condenó por un delito de lesiones graves del artículo 149.2, apreciando la atenuante de error vencible, imponiendo una pena de dos años de prisión. En el juicio, FD alegó que la práctica de la ablación había tenido lugar cuando su hija estaba al cuidado de su madre, abuela de la niña, mientras FD trabajaba en el campo. El Tribunal no concedió validez a esta declaración y señaló que no había duda alguna de la autoría de la madre. La sentencia condenatoria fue recurrida por 
FD ante el Tribunal Supremo, alegando vulneración del derecho a la presunción de inocencia por violación del principio in dubio pro reo. El Tribunal Supremo, en su Sentencia de 16 de diciembre de 2013, le da la razón, y absuelve a FD. En primer lugar, el Tribunal aduce que si, como señala el Fiscal, «no consta la forma y circunstancias en que se ha mutilado a la niña», no es posible construir una prueba de cargo válida que demuestre la participación directa de la madre en los hechos. Por otra parte, la responsabilidad por omisión derivada del deber de garante recogido en el artículo 11 del Código Penal (responsabilidad que sustentó la sentencia condenatoria de la Audiencia Nacional), sólo se explicaría si FD tuviera constancia de la prohibición y lesividad de la práctica, algo que no se considera probado, ya que la misma es contemplada en su lugar de origen como una actuación socialmente obligada».

Este caso pone de relieve los importantes dilemas que la aplicación práctica del Derecho Penal presenta en los casos de mutilación genital femenina. Es preciso destacar que la mutilación de la niña se había llevado a cabo en el país de origen, y que la presencia de la niña y la madre en España se deriva del ejercicio por parte del padre al derecho a la reagrupación familiar. El derecho a la reagrupación o reunificación familiar es el derecho de los migrantes a mantener la unidad de su familia. Este derecho encuentra su justificación en otros fundamentales, reconocidos en Tratados y en el Derecho Internacional de los Derecho humanos, como son el derecho a la intimidad en el ámbito familiar ${ }^{28}$. En cumplimiento de esta Directiva, la mayoría de los países europeos incluye en su legislación sobre extranjería los procedimientos para hacer efectivo este derecho ${ }^{29}$. El problema que se presenta en la práctica es que este derecho se puede ver seriamente obstaculizado con la prohibición penal de la MGF: si un migrante se plantea hacer efectiva la reagrupación, la posibilidad de que la llegada de sus hijas mutiladas al país en el que reside termine con un proceso penal y penas de cárcel para él o para su mujer, madre de las menores, se consolida como un elemento claramente disuasorio de su legítima pretensión. En definitiva, como señala Francisco Jiménez, el miedo a las condenas en los países de

${ }^{28}$ En el ámbito de la Unión Europea, la Directiva 2003/86/CE del Consejo, de 22 de septiembre de 2003, sobre el derecho a la reagrupación familiar, tiene como objetivo establecer normas comunes que permitan a los miembros de la familia de los nacionales de fuera de la UE que residen legalmente en el territorio de la Unión Europea (UE) que se reúnan con ellos en el país donde residen.

${ }_{29}$ En España, la Ley Orgánica 4/2000, de 11 de enero, sobre derechos y libertades de los extranjeros en España y su integración social (artículos del 16 al 19) y el Reglamento de la Ley Orgánica 4/2000, aprobado por Real Decreto 557/2011, de 20 de abril (artículos del 52 al 58). 
destino no sólo impide la reagrupación familiar, sino que propicia la permanencia en los países de origen, donde es más difícil escapar de la práctica de esta tradición ${ }^{30}$.

\section{Recapitulación y propuestas parciales: el Derecho penal como parte de una respuesta social guiada por el principio de integración}

Las voces críticas que demandan la superación de una posición etnocéntrica en el tratamiento de la MGF han contribuido positivamente a mantener una actitud reflexiva que advierte de la complejidad del problema y las dificultades de tratamiento en los países de destino. Un análisis más detenido en torno a las razones que explican la pervivencia de esta práctica ha arrojado como tesis mayoritaria el interés en el control de la sexualidad de la mujer: con la mutilación se garantiza la pureza, la virginidad, el sometimiento de la mujer y con todo ello el honor de la familia ${ }^{31}$. Como narra Asha Ismail ${ }^{32}$, «la MGF es una de las armas que (los hombres) utilizan para que la mujer sea sumisa, para que obedezca (...) Lo que ocurre es que esos hombres, en esas comunidades, eligen para casarse a una mujer mutilada, porque la mujer que va a ser su esposa y la madre de sus hijos tiene que serlo», y añade «tienes que casarte porque la existencia de una mujer en esas culturas es nacer, crecer, casarse, servir a su marido, tener tantos hijos como pueda $(\ldots) »$.

La comprensión de la mujer como ser inferior, subordinada al hombre, que encuentra su función social en el matrimonio y la maternidad no es exclusiva de las culturas que practican la MGF, sino que es un tópico mundial, más evidenciado en aquellas regiones que han alcanzado menor desarrollo social y político, y en la que perviven prácticas como los matrimonios forzados, el castigo del adulterio, los homicidios por motivos de honor y la imposición en general de prácticas que garantizan ese control. Pero

30 Francisco Jiménez García, «La mutilación genital femenina (MGF) y el principio de extraterritorialidad. A propósito de la sentencia de la Audiencia Nacional 9/2013 de 4 de abril de 2013», Revista española de Derecho Internacional, vol. LXV, núm.2 (2013): 356.

${ }^{31}$ Cfr. en este sentido, Anika Rahman y Nahid Toubia, Female Genital Mutilation. A Practical Guide to Worldwide Laws and Policies (Londres: Zed Books, 2000), 4-5; María Dolores Adam Muñoz, La mutilación genital femenina y sus posibles soluciones desde la perspectiva del Derecho Internacional Privado (Córdoba: Universidad de Córdoba, 2004), 30; Bénédicte Lucas, «Aproximación antropológica a la práctica de la ablación o mutilación genital femenina», Cuadernos electrónicos de filosofía del Derecho 17 (2008): 6-7; Torres Fernández, «La mutilación genital femenina...», 13.

32 Asha Ismail, entrevista por María Gascón, publicada en «Página abierta» 236, enerofebrero de 2015, disponible en http://www.pensamientocritico.org/ashism0215.htm. 
la asimetría en las relaciones entre el hombre y la mujer no es exclusiva de estas regiones, sino que pervive en la mayoría de los países y sigue apoyándose esencialmente en la consideración de la mujer como posesión del hombre, sobre todo en el ámbito de la sexualidad. La exaltación de la virginidad de las mujeres es un referente universal, presente en casi la totalidad de las religiones y en la base de muchas de las convenciones culturales. En el mundo occidental, las mujeres se enfrentan a modelos sociales contradictorios, que les animan a una sexualización desde edades cada vez más tempranas $^{33}$, pero que por otro promueven que sean despreciadas si ejercen su sexualidad con libertad. Esta universalidad en los parámetros sobre las relaciones entre hombres y mujeres debe contribuir a la relativización de la postura de la superioridad moral con la que afrontar el problema de la MGF y favorecer un análisis más detenido que huya de la simplificación que considera estas prácticas como una «aberración» extraña a nuestro bagaje cultural superior ${ }^{34}$.

Ahora bien, este reconocimiento no significa que se proponga una minimización de las lesiones que esta práctica representa ${ }^{35}$ : como se ha señalado más arriba, no sólo se han demostrado médicamente las secuelas de la intervención en la integridad física y la salud, sino que la mutilación realizada sobre las niñas, que no tienen capacidad para consentir, encierra en sí misma un atentado contra la dignidad y representa un trato degradante. El reconocimiento de la práctica de la MGF como una grave lesión de derechos fundamentales universalmente reconocidos es un paso adelante irrenunciable en la lucha contra la misma y en general, en la erradicación de tradiciones lesivas para los derechos humanos. No deberíamos olvidar, como destaca Nuria Merchal, que sólo recientemente la MGF ha dejado de ser considerada un asunto privado, al igual que otras prácticas de violencia

${ }^{33}$ Sexualización que impone un modelo de apariencia física en el que se incluyen prácticas agresivas sobre el cuerpo, como la implantación de mamas, depilación, cirugía estética con carácter general y en algunos casos también genital.

${ }^{34}$ Como destaca Adela Asúa, «Criminología y multiculturalismo...», 88-89, la idea de la inferioridad natural de la mujer no es ajena a la cultura occidental, en la que ha estado presente la supeditación de la mujer a su «destino» como esposa y madre. Adela Asúa señala los ejemplos vigentes en la ley penal española y en la práctica de los tribunales que respondían al ideario de la consideración de la mujer como posesión sexual del hombre: el «uxoricidio» (matar a la esposa que era sorprendida en adulterio) se castigaba con el destierro y no merecía pena de prisión, el «infanticidio» (matar al hijo recién nacido para ocultar la deshonra) merecía cierta comprensión y una pena inferior al homicidio, la jurisprudencia rechazaba la violación en el matrimonio, entre otros.

${ }^{35}$ María Caterina La Barbera cree sin embargo que no debe asumirse sin mayores explicaciones que todas las intervenciones genitales sean lesivas o creen disfunción sexual («Mujeres, migración y Derecho Penal...», 54-56). 
contra las mujeres en el ámbito de las familias y las comunidades ${ }^{36}$. A pesar de que ya en 1948 la Declaración Universal de Derechos humanos recoge en su artículo 2 el reconocimiento de los derechos sin discriminación basada en el sexo ${ }^{37}$, e igualmente se pronuncian el Pacto Internacional de Derechos Civiles y Políticos de $1966^{38}$ y el Pacto Internacional de Derechos Económicos, Sociales y Culturales también de $1966^{39}$, la superación de una comprensión antropológica de los derechos humanos (que no concede la visibilidad requerida para la protección específica de mujeres y niños) no comienza a plantearse hasta unos años después, cristalizándose en la Convención de NU sobre la Eliminación de todas las Formas de Discriminación contra la Mujer de $1979^{40}$ y en la Declaración de NU sobre la Eliminación de la Violencia contra la Mujer, de $1993^{41}$. En el ámbito específico de protección de los menores, la Convención de NU sobre los Derecho del Niño (que entró en vigor en 1990) señala en su artículo 24.3 que «Los Estados Partes adoptarán todas las medidas eficaces y apropiadas posibles para abolir las prácticas tradicionales que sean perjudiciales para la salud de los niños».

De este modo se instituye una «conciencia jurídica internacional» ${ }^{42}$, que reconoce dos principios esenciales: la necesidad de favorecer una protección específica para mujeres y niños y el rechazo de que las prácticas tradicionales lesivas puedan legitimarse en convicciones religiosas o cul-

${ }^{36}$ Nuria Merchal Escalona, «Mutilación genital femenina y violencia de género», en Actas del I Congreso Internacional sobre Migraciones en Andalucía, ed. por Francisco Javier García Castaño y Nina Kressova (Granada: Instituto de Migraciones, 2011), 2179.

37 Artículo 2 de la Declaración universal de los derechos del hombre (adoptada el 10 de diciembre de 1948, Resolución 217 de la Asamblea General, UN Doc. A/810):

«Toda persona tiene los derechos y libertades proclamados en esta Declaración, sin distinción alguna de raza, color, sexo, idioma, religión, opinión política de cualquier otra índole, origen nacional o social, posición económica, nacimiento o cualquier otra condición»

38 Pacto Internacional de Derechos Civiles y Políticos, adoptado el 16 de diciembre de 1966 (entrada en vigor el 23 de marzo de 1976), concretamente artículos 2 y 26.

39 Pacto Internacional de Derechos Económicos, Sociales y Culturales, adoptado el 16 de diciembre de 1966 (entrada en vigor el 3 de enero de 1976), concretamente artículo 2.

40 Adoptada el 18 de diciembre de 1979, con entrada en vigor el 3 de septiembre de 1981. Esta Convención requiere expresamente a los Estados, en su artículo 5, para que trabajen en la eliminación de los prejuicios y de las prácticas consuetudinarias que estén basados en la idea de superioridad o inferioridad de los sexos.

${ }^{41}$ Declaración de la Asamblea General de Naciones Unidas, adoptada en la 85. ${ }^{\text {a }}$ Sesión Plenaria, el 20 de diciembre de 1993, que establece en su artículo 4 que los Estados no deben invocar ninguna costumbre, tradición o consideración religiosa para eludir su obligación de eliminar la violencia contra la mujer.

${ }^{42}$ Expone esta idea Jiménez García, «La mutilación genital femenina y el principio de extraterritorialidad», 352 . 
turales ${ }^{43}$. Con ello, el interés en la diversidad cultural no puede ser argüido para mantener tradiciones que perpetúan la discriminación y amparan la lesión de derechos humanos. Y esto es así tanto en los países originarios de las prácticas como en aquellos que reciben inmigrantes con estas tradiciones: por ello, la invocación a la diversidad no resulta ser suficiente para legitimar la pasividad ante la violación de los derechos humanos.

Llegados a este punto nos encontramos con dos conclusiones de compleja conciliación entre sí. Por un lado, es muy difícil discutir en la actualidad que la MGF representa una clara vulneración de derechos fundamentales que no puede ser justificada en prácticas tradicionales; más aún cuando estas prácticas se sostienen en una discriminación sexista que tiene como fin el control de la sexualidad de las mujeres, y que representa, en consecuencia, un acto de violencia de género. Esta convicción se ha asentado por fin en Derecho Internacional y ha determinado la adopción de medidas diversas, entre ellas las penales. Pero, por otro lado, sería injusto desatender el choque cultural que se produce cuando las mujeres emigran desde sus países de origen, en los que las reglas sociales impulsan a la práctica de la MGF para garantizar la inserción social de las niñas, hasta los países de destino en los que son juzgadas como criminales, pudiendo serles impuestas penas privativas de libertad o la pérdida de la patria potestad sobre sus hijas ${ }^{44}$. Y también sería injusto no tener en cuenta los efectos que para los intereses de las menores y de las familias implicadas se derivan de la respuesta penal, especialmente el desaliento para la reagrupación familiar.

¿Cómo conciliar estas consideraciones? En primer lugar, rechazando una simplificación basada en una supuesta superioridad moral de occidente y aceptando la complejidad del problema ${ }^{45}$, lo que exige un acercamiento multidisciplinar al mismo ${ }^{46}$. La respuesta penal será más legítima cuando realmente sea la última ratio, cuando hayan fracasado la educa-

${ }^{43}$ Estos axiomas son recogidos en distintos instrumentos y acciones de Derecho Internacional, como la Declaración sobre la eliminación de todas las formas de intolerancia y discriminación fundadas en la religión o las convicciones, proclamada por la Asamblea General de UN el 25 de noviembre de 1981 (resolución 36/55), que insta a la protección de los derechos de los niños y niñas contra los abusos cometidos en nombre de una creencia o tradición cultural concreta y la Cuarta Conferencia Mundial sobre la mujer en Pekín, de 1995. También recoge la necesidad de la protección especial el Protocolo a la Carta Africana de los derechos del hombre y de los pueblos, relativo a los derechos de la mujer en África (Protocolo de Maputo), adoptado el 11 de julio de 2003, Asamblea de la Unión Africana (entrada en vigor: el 25 de noviembre de 2005).

44 En sentido similar, Adela Asúa, «Criminología y multiculturamlismo...», 94.

${ }^{45}$ En este sentido, Adela Asúa, «Criminología y multiculturalismo...», 82.

46 Rocío Salamanca de Dueñas, «Dossier II: Mutilación genital femenina...», 29. 
ción, la prevención y la integración. Por ello, con carácter universal es necesario acentuar las medidas nacionales y trasnacionales encaminadas a la prevención y, en concreto en los países occidentales, asumir un concepto de integración que implique el reconocimiento esencial de la dignidad de todas las personas implicadas. Es preciso contribuir al empoderamiento de las mujeres africanas (que son las mayoritariamente afectadas), favoreciendo el contacto de las mismas con las organizaciones no gubernamentales y las instituciones estatales e internacionales que trabajan en la educación precisamente a partir de las propias voces de mujeres ${ }^{47}$ afectadas que contribuyen la erradicación de la MFG (y a partir de ahí extender los programas de prevención también con la implicación de los hombres, sin la cual no es posible acabar con esta tradición, especialmente en las estructuras sociales tribales).

En segundo lugar, es necesario favorecer una clarificación conceptual que contribuya a una mejor comprensión del fenómeno. La MGF, como se ha señalado, se produce sobre niñas y representa una práctica que tiene como objetivo esencial la adjudicación de un rol de sometimiento de las mujeres en un aspecto tan esencial para las personas como es la sexualidad. Si recordamos que el control de la sexualidad de la mujer es una práctica extendida prácticamente en todas las culturas, tendremos mayor capacidad para acercarnos a este fenómeno desde dos perspectivas distintas. Por un lado, advirtiendo que la discriminación sexista que se encuentra en la base del mismo no nos es ajena, por lo que cualquier reacción no puede basarse en una superioridad moral. Por otro, reconociendo que en todo caso el Derecho Penal ha de intervenir de igual modo que ha de hacerlo en otros supuestos de violencia de género, ante la lesión de bienes jurídicos fundamentales. Sin embargo, esto no puede conducir a una equiparación de la MFG con otras prácticas sociales que inciden en el cuerpo de la mujer (operaciones estéticas y otras) ${ }^{48}$, ya que la MGF, ante todo, se lleva a cabo sobre niñas sin capacidad de consentimiento e implican una mutilación con efectos en la salud y en el disfrute de la sexualidad. Este elemento, la realización sobre niñas, confiere a la MGF una gravedad especial que no puede ser discutida a la que se suma la consideración de la

47 En este sentido, Alfonso Serrano Maíllo, «El secuestro de la mutilación genital femenina: devolviendo la voz a sus protagonistas», reseña de Beyond the dances. Voices of women on female genital mutilation, de V. Barungi y H. Twongyeirwe (Eds.), Kampala: FEMRITE, 2009, en Revista de Derecho UNED, Núm. 7, 2010, 652. También Isabel Ortega destaca como la asunción de una posición etnocéntrica, que no tiene en cuenta la lucha de las propias mujeres africanas, conduce a la «alterización» y a la presunción de superioridad moral («Narrativas periodísticas en torno a la ablación...», 1894).

48 Sí que realiza esta comparación Isabel Ortega, «Narrativas periodísticas en torno a la ablación...», 1893. 
misma como un acto de violencia de género. Esta doble comprensión es la única que facilita una correcta comprensión del fenómeno ${ }^{49}$.

Desde un punto de vista más concreto, la propuesta defendida, a saber, priorizar la respuesta social y la integración en los países de destino, aunque manteniendo una necesaria intervención penal sometida a límites y cautelas, exige tener en cuenta la posibilidad de aplicar circunstancias eximentes o atenuantes recogidas en la ley, que tienen que ver con las dificultades para interiorizar unas normas sociales contradictoras con los valores asumidos desde la infancia en los países de origen, La vía más adecuada para recoger esta posibilidad es el error de prohibición, que permite aminorar la pena, al menos, en los casos en los que cabe probar un desconocimiento del alcance de la prohibición en torno a estas conductas $^{50}$.

Igualmente es preciso plantearse hasta qué punto tiene sentido extender la jurisdicción de los Tribunales españoles hasta las mutilaciones realizadas en los países de origen antes de la llegada a España. Esto es lo que vemos a continuación.

\section{Jurisdicción internacional, asilo y refugio en los supuestos de MGF. Algunas contradicciones}

La aparición de casos de MGF en los países occidentales, destino de inmigrantes de origen subsahariano entre los que se encuentra fuertemente arraigada esta práctica, planteó en el terreno jurídico dos cuestiones esenciales. Por un lado, de la de si resultaba necesaria una tipificación expresa en las leyes penales nacionales de esta clase de mutilación o sin embargo bastaban las previsiones tradicionales que penalizan las lesiones (entre las que cabe encuadrar la mutilación genital). En el Derecho Europeo, ha resultado hasta ahora mayoritaria la posición contraria a una regulación expresa

49 Algunos autores sin embargo creen que la MGF no es propiamente un acto de violencia de género ya que no todas las mujeres del mundo tienen la posibilidad de ser víctimas (María Dolores Serrano Tárraga, «Diversidad cultural y ordenamiento jurídico penal: el delito de mutilación genital femenina en el Código Penal español», en Gestión de la diversidad cultural en las sociedades contemporáneas, ed. por María Teresa Regueiro García, 409. Valencia: 2014). A favor de la consideración de la misma como violencia de género Carmen Vallejo Peña, «Mutilación genital femenina: violencia de género con nuevas trabas para su persecución en España», Revista de Estudios Jurídicos Universidad de Jaén n. ${ }^{\circ} 14$ (2014): 2-3.

50 Plantean esta posibilidad Nieves Sanz, «Diversidad cultural y política criminal...», 11-12, Adela Asúa, «Criminología y Multiculturalismo...», 86. En contra de esta posibilidad, Rocío Salamanca, «Dossier II: Mutilación genital femenina...», 93. 
que sólo algunos países han incorporado ${ }^{51}$. Por otro lado, la de si en aras de una efectiva persecución cabría incluir la MGF como un delito de persecución universal, de manera que los países de destino pudieran juzgar no sólo las mutilaciones cometidas en su territorio, sino también las llevadas a cabo en los países de origen, tanto si la mutilación tuvo lugar cuando la niña aún no se había desplazado con la familia a Occidente, como si se llevaba a cabo en un desplazamiento de «vacaciones», después de haber llegado a un país occidental.

En España, esta última cuestión se resolvió en un primer momento a favor de la jurisdicción universal, priorizando una intervención penal máxima de los Tribunales, incluso en aquellos casos en los que la MGF se hubiera realizado en los países de origen antes del desplazamiento. Con este fin, se procedió a reformar el artículo 23 de la Ley Orgánica del Poder Judicial (LPOJ) en 2005, y la MGF fue incluida en el número 4 del artículo 23, como uno de los graves delitos que permite la justicia mundial, aunque exigiéndose un criterio de vinculación, como es el hecho de que los responsables se encontrasen en España:

Artículo 23. (Versión vigente entre el 10/07/2005 y el 20/11/2007)

1. En el orden penal corresponderá la jurisdicción española el conocimiento de las causas por delitos y faltas acometidos en territorio español o cometidos a bordo de buques o aeronaves españoles, sin perjuicio de lo previsto en los tratados internacionales en que España sea parte.

(...)

4. Igualmente será competente la jurisdicción española para conocer de los hechos cometidos por españoles o extranjeros fuera del territorio nacional susceptibles de tipificarse, según la ley penal española, como alguno de los siguientes delitos:

(...)

g) Los relativos a la mutilación genital femenina, siempre que los responsables se encuentren en España.

Sin embargo, los problemas internacionales y diplomáticos planteados por la aplicación de este principio por parte de los Tribunales españoles, favorecieron una nueva reforma con el objetivo de limitar el alcance de la jurisdicción universal, en 2014 (Ley 1/2014, de 13 de marzo, de Reforma de

${ }^{51}$ Incluyen una tipificación expresa de la MGF: Austria, Bélgica, Chipre, Dinamarca, Irlanda, Italia, España, Croacia, Suecia y Reino Unido. Véase un análisis detenido sobre esta cuestión en Female genital mutilation in the European Union and Croatia. European Institute for Gender Equality, 2013.

http://eige.europa.eu/sites/default/files/documents/eige-report-fgm-in-the-eu-and-croatia.pdf 
la Ley Orgánica del Poder Judicial), de manera que la competencia de los Tribunales españoles en estos casos ya no puede sustentarse únicamente en el principio de justicia mundial frente a la gravedad de los hechos, sino que se exige un vínculo de conexión con España y la ausencia de conflictos con otros Estados. Con esta reforma, la MGF ya no aparece expresamente mencionada, aunque pudiera ser uno de los supuestos que permite la jurisdicción de los Tribunales españoles, al consistir en un acto de violencia de género $^{52}$. Según esta nueva regulación, para que los Tribunales españoles puedan conocer los hechos será necesario: que el presunto culpable sea español o extranjero con residencia habitual en España, o que la víctima tuviera nacionalidad española o residencia habitual en España, en el momento de la comisión de los hechos.

En definitiva, la Reforma de 2014 de la LPOJ española ha restringido la aplicabilidad del principio de jurisdicción universal en los casos de MGF. Esta decisión ha sido criticada por algunos autores que consideran prioritaria la intervención penal y creen, por ello, que dicha limitación no contribuye a la erradicación de esta práctica a nivel mundial ${ }^{53}$. Sin embargo, es preciso advertir que, a pesar de la restricción, la ley permite la competencia de los tribunales españoles, siempre, al menos, que los posibles autores ten-

52 Artículo 23 de la LOPJ. (Versión vigente tras la reforma introducida por la Ley Orgánica $1 / 2014$ )

1. En el orden penal corresponderá la jurisdicción española el conocimiento de las causas por delitos y faltas cometidos en territorio español o cometidos a bordo de buques o aeronaves españoles, sin perjuicio de lo previsto en los tratados internacionales en que España sea parte.

(...)

4. Igualmente, será competente la jurisdicción española para conocer de los hechos cometidos por españoles o extranjeros fuera del territorio nacional susceptibles de tipificarse, según la ley española, como alguno de los siguientes delitos cuando se cumplan las condiciones expresadas:

(...) 1) Delitos regulados en el Convenio del Consejo de Europa de 11 de mayo de 2011 sobre prevención y lucha contra la violencia contra las mujeres y la violencia doméstica, siempre que:

1. ${ }^{\circ}$ el procedimiento se dirija contra un español;

2. ${ }^{\circ}$ el procedimiento se dirija contra un extranjero que resida habitualmente en España; o,

3. ${ }^{\circ}$ el delito se hubiera cometido contra una víctima que, en el momento de comisión de los hechos, tuviera nacionalidad española o residencia habitual en España, siempre que la persona a la que se impute la comisión del hecho delictivo se encuentre en España.

53 Vallejo Peña, Carmen, «Mutilación genital femenina...», 21. Antes de la Reforma, a favor de esta jurisdicción universal también María Dolores Serrano Tárraga, «Violencia de género y extraterritorialidad de la ley penal. La persecución de la mutilación genital femenina», Revista de Derecho Uned, n. ${ }^{\circ} 11$ (2012): 884-886. 
gan como mínimo residencia habitual en España. Puesto que la responsabilidad en estos casos se atribuye a los padres, ya sea por intervención directa (en grado de autoría, inducción o cooperación necesaria) o por omisión, con infracción del deber de garante, la posibilidad de intervención penal subsiste con independencia del tiempo o lugar de la comisión de los hechos. Precisamente, la restricción operada por la Reforma será juzgada como insuficiente para otro sector de opinión que considera que dicha intervención imposibilita la reagrupación familiar, tal y como más arriba veíamos: si la llegada a España de esposa e hijas de los inmigrantes (la mayoría ya mutiladas en los países de origen) puede suponer una condena penal para la madre o para ambos progenitores, cabe esperar que el derecho a la reagrupación no pueda ser ejercido ${ }^{54}$.

Efectivamente, este recurso a la intervención penal para juzgar las mutilaciones producidas en los países de origen antes de iniciar la migración, impide tomar en consideración las diferencias socio culturales que se encuentran en el sustrato de valores asumidos en las distintas sociedades, como una posible atenuante que conceda una razonable armonización entre las respuestas penales y las educativas. Y, por otra parte, parece incidir en la impresión de que la jurisdicción universal resulta haber sido creada para los africanos, los más desfavorecidos a nivel económico y social, y quienes con mayor frecuencia deben asumir responsabilidades por crímenes internacionales, como si sólo en África tuvieran lugar hechos de estas características. En conexión con ello, Daniel R. Pastor ha advertido que la legitimidad de las Cortes penales internacionales queda en entredicho desde el momento en que en la práctica no cabe hablar de «sociedad mundial» homogénea ni de «comunidad internacional», sino de un mundo dividido entre una minoría rica y poderosa y una mayoría condenada a la pobreza, el hambre y la guerra. En estas circunstancias, continúa este autor la falta de desarrollo equitativo y las limitaciones del derecho a la migración impiden hablar de «ciudadanía universal» ${ }^{55}$.

Po último, resulta especialmente difícil sustentar la jurisdicción universal y la intervención penal para juzgar las mutilaciones cometidas en los

${ }^{54}$ En esta dirección, Adela Asúa recuerda que uno de los votos particulares en el Comité Nacional de Bioética en Italia, en el informe sobre la MGF de 1998, concretamente el firmado por Sergio Stamatti, defendía que, sin negar la condena de la MGF y la necesidad de la prohibición general de tales prácticas, sería adecuado reservar la sanción penal para aquellas personas que, establecida su residencia en el país de acogida durante un tiempo, pretendieran continuar con la práctica («Criminología y multiculturalismo...», 95). Expone también las dificultades para la reagrupación familiar, Francisco Jiménez, «La mutilación genital femenina...», 356 .

55 Daniel R. Pastor, El poder penal internacional. Una aproximación jurídica crítica a los fundamentos del Estatuto de Roma (Barcelona: Atelier, 2006), 65-90. 
países de origen sobre la base de la grave violación de derechos humanos, y después mantener una posición restrictiva en la concesión del derecho de asilo. Como señala Adela Asúa ${ }^{56}$, el reconocimiento del asilo en los casos de MGF representa un indicador del grado de compromiso en la protección de las víctimas de esta práctica y de la legitimidad de la intervención. Y en este ámbito nos encontramos con los siguientes problemas.

En primer lugar, hasta hace apenas unos años, las demandas de asilo basadas en razones de género no estaban expresamente reguladas, y tenían difícil acomodo legal ${ }^{57}$. El carácter androcéntrico en las Convenciones de los derechos humanos se apreciaba igualmente en la Convención de Ginebra de 1951 sobre el Estatuto de los Refugiados, en la que se desconoce la persecución por razón de sexo. La necesidad de reinterpretar la definición de refugiado desde una perspectiva de género ha sido reclamada por un importante sector de la doctrina ${ }^{58}$, que ha puesto de relieve las reticencias de los Gobiernos y del propio Tribunal Europeo de Derechos Humanos para admitir la violencia de género como causa de asilo. La incorporación de las experiencias de las mujeres y, en definitiva, del enfoque de género, ha producido una transformación paulatina en este ámbito, de modo que concretamente en España la Ley 12/2009, de 30 de octubre, reguladora del derecho de asilo y de la protección subsidiaria, incluye el género en su artículo 3 como causa de persecución que puede dar lugar a la condición de refugiado.

Sin embargo, la efectiva práctica de esta protección, en segundo lugar, se ve entorpecida por la inexistencia de un consenso en torno a la definición de la lesión que representa la MGF y por su consideración como un aspecto de la privacidad, ligado a la esfera más íntima de las personas. De este modo, y a pesar de los avances, todavía no parece existir una idea clara entre las mujeres africanas sobre el alcance de esta práctica. La lentitud con la que evolucionan las sociedades en las que esta tradición está arraigada impide hablar de una conciencia colectiva sobre la lesividad de la misma: hasta ahora, son más las mujeres que perpetúan la tradición sobre sus hijas, con el objeto de que no sean marginadas socialmente, que las que huyen buscando refugio para escapar de ella. La pobreza, el fuerte patriarcado y el constreñimiento cultural no sólo dificultan el cambio de perspec-

56 Adela Asúa, «Criminología y Multiculturalismo...», 100.

57 Víctor M. Merino i Sancho, «Derecho de asilo y género. ¿Ha evolucionado el derecho de asilo?», Cuadernos electrónicos de filosofía del Derecho 17 (2008): 3-5.

${ }^{58} \mathrm{Cfr}$. Ana Valero Heredia, «Derecho de asilo y mutilación genital femenina», Cuadernos de Derecho Público, n. ${ }^{\circ} 30$ (2007): 79-82; Carmen Miguel Juan, «La mutilación genital femenina, derecho de asilo en España y otras formas de protección internacional». Cuadernos Electrónicos de filosofía del Derecho 17 (2008): 1-4; Tamar Pitch, Un derecho para dos. La construcción jurídica de género, sexo y sexualidad (Madrid: Trotta, 2003), 259. 
tiva, sino que, en el caso de que éste se produzca, imponen fuertes barreras para escapar de la tradición. Pero también en los países de destino todavía se muestran reticencias para la concesión del asilo. En el caso de España, la actividad de los Tribunales en la persecución penal de la MGF, recurriendo incluso a la jurisdicción universal, contrasta con la irrelevancia de las cifras en las peticiones de asilo ${ }^{59}$, y la tendencia mayoritaria de la Jurisdicción contencioso-administrativo que rechaza la concesión ${ }^{60}$.

En definitiva, a pesar de los avances en este tema, existen algunas contradicciones que arrancan de la inexistencia de un consenso claro en la definición del fenómeno. Las mujeres que nacen en las sociedades en las que la MGF está arraigada, la sufren en primer lugar siendo niñas como víctimas, con una intervención que lesiona su integridad moral y atenta contra su salud e integridad física. Sin embargo, crecen luego en un entorno como mujeres que advierten muy nítidamente que la mutilación garantiza su integración social, y el interiorizado miedo a la exclusión las convierte en partícipes de las mutilaciones practicadas sobre sus propias hijas. Si por alguna razón acceden a una perspectiva diferente que les aporta referencias negativas sobre lo sufrido (o sobre lo que pueden sufrir si la MGF se ha retrasado y se impone solicitada por el futuro marido), la posibilidad de escapar de la misma, al igual que ocurre en otros casos de violencia de género, en los que el agresor es la propia familia y la víctima es alguien sin relevancia, como ocurre a las mujeres, es mínima.

Y esta confusión se traslada a Occidente. Condenamos enérgicamente la práctica, recurrimos a la intervención penal, y en algún momento, cuando hay que meter a la cárcel varios años a la mujer mutilada, por haber mutilado a su hija, apartándola de la misma y dejando a la menor en manos del padre (quien alega que él no sabía nada porque esto es una cosa de mujeres) o bajo la tutela del Estado, entonces nos damos cuenta que, en contra del maniqueísmo y la simplificación que nos alivia, concluimos que no sabemos quiénes son las víctimas y quiénes los verdugos, y que tal vez de este modo cooperamos a la desprotección de las menores.

59 United Nations High Commissioner for Refugees. «Mutilations génitales féminines et asile dans l'Union Européenne». New York, 2013. Acceso el 30 de noviembre de 2016.

http://www.refworld.org/cgi-bin/texis/vtx/rwmain/opendocpdf.pdf?reldoc= y\&docid $=5163$ edf 14

${ }^{60}$ Rechazan la concesión del asilo las siguientes resoluciones: Auto del Tribunal Supremo de 17 de julio de 2014; Sentencia de la Audiencia Nacional, de 10 de febrero de 2004; Sentencia la Audiencia Nacional, de 24 de marzo de 2006; Sentencia del Tribunal Supremo, de 4 de julio de 2008; Sentencia del Tribunal Supremo, de 2 de febrero de 2015. Conceden: Sentencia del Tribunal Supremo, de 11 de mayo de 2009; Sentencia de la Audiencia Nacional, de 21 de junio de 2006; Sentencia de la Audiencia Nacional, de 24 de noviembre de 2015. 
Tal vez deberíamos empezar por aclararnos. Por definir claramente la MGF como un acto de violencia de género, lo que exige comenzar por conceptualizar la violencia de género en sí misma. Por establecer con nitidez unos estándares en la comprensión de un fenómeno cuya complejidad exige afrontar con rigor y valentía una respuesta estructural que articule medidas de distinto calado (entre las que el Derecho Penal sea realmente la última ratio) y por aceptar de una vez por todas que la violencia de género, y entre ellas la MGF como es una grave consecuencia de una situación de desigualdad entre sexos y de sometimiento de las mujeres a distintos niveles. El empecinamiento en definir el problema sobre la diferenciación entre víctimaverdugo, no contribuye a resolver este reto con la justicia que merece.

¿Caminamos en esta dirección? En mi opinión, no lo suficiente. La política de la Unión Europea al respecto, centrada esencialmente en la atención a las víctimas, puede ser significativa, por sus deficiencias, de la necesidad de definir la violencia de género con la mayor precisión.

\section{Conclusiones: por una política decidida en la Unión Europea contra la violencia de género y la MGF}

La violencia de género no se refiere a los actos de violencia de hombres sobre mujeres. Es un fenómeno mucho más complejo en el que la violencia en el ámbito de la pareja es sólo un exponente. La simplificación que reduce el problema a una especie de enfrentamiento entre hombre-mujer es pueril e impide un tratamiento digno de este grave problema. Para alcanzar una comprensión más acertada conviene escapar de una asignación de roles «víctimas-verdugos» que tiene efectos negativos: genera reticencias e impide un entendimiento más profundo del problema. Por ejemplo, en el caso de la MGF es cierto que la práctica se perpetúa de manera directa con la intervención de las propias mujeres: son las mujeres las que se encargan de «gestionar» una intervención sobre los genitales femeninos. Por ello, se habla de «cosas de mujeres». Sin embargo, a nadie se le escapa, gracias especialmente a las mujeres africanas que se han revelado contra ella, que la perpetuación se deriva del sometimiento de la mujer a una creencia sobre su propia sexualidad, impuesta por valores patriarcales que exigen la virginidad en las mujeres antes del matrimonio. La «posesión sexual» que los hombres esperan sólo es válida si resulta ser exclusiva. Esta comprensión, como vimos, no está tan sólo detrás de la MGF, sino de otras tradiciones de sometimiento en culturas diversas.

Por ello, en el tratamiento de la violencia de género debería ser esencial en todo caso acometer su definición, y afrontarlo como un problema de toda la sociedad, que exige cambios estructurales, sin que la mera atención a las 
víctimas baste para hacerle frente. En el ámbito de la MGF nos acaba confundiendo el hecho de que las víctimas coincidan con los responsables de la agresión. En el contexto general de la violencia de género, la respuesta sobre víctimas concretas, de agresiones denunciadas y perseguidas, contribuye a tranquilizar la conciencia social al centrar el problema en individuos concretos, pero será siempre una solución sólo a medias hasta que no comprendamos que las raíces de este fenómeno se hallan en la propia conformación social de carácter patriarcal.

No cabe duda de que en la Unión Europea existe una fuerte conciencia en torno a la violencia de género ${ }^{61}$, que se traduce en un considerable número de medidas de carácter jurídico ${ }^{62}$ y político, con el desarrollo de diversos programas dirigidos a la atención de las víctimas. Sin embargo, como destaca Magdalena Martín ${ }^{63}$, aunque el Tratado de la Unión Europea, el Tratado de Funcionamiento de la Unión Europea y la Carta de Derechos Fundamentales proclaman el respeto de la dignidad humana, la no discriminación activa y la igualdad entre hombres y mujeres, no se ha establecido un título competencial que permita a la Unión Europea legislar en esta materia. Esto ha contribuido a la falta de una definición propia de violencia de género y de una legislación específica ${ }^{64}$, a una importante dispersión normativa y a una deficitaria armonización legislativa y político criminal entre los países miembros ${ }^{65}$.

En este contexto, la Unión Europea ha centrado su esfuerzo en la Orden Europea de Protección, instrumento de cooperación judicial que permite extender las medidas de protección sobre las víctimas con independencia del país de la UE en el que éstas se encuentren. Sin menoscabar las consecuencias positivas en la atención a las víctimas, la implementación de la Orden

${ }^{61}$ En este sentido, María Morgade Cortés, «La Orden Europea de Protección como instrumento tuitivo de las víctimas de la violencia de género». Cuaderno Electrónico de Estudios Jurídicos n. ${ }^{\circ} 3$ (2014): 80-81.

${ }^{62}$ La Directiva 2012/29/UE del Parlamento Europeo y del Consejo, de 25 de octubre de 2012, por la que se establecen normas mínimas sobre el apoyo y la protección de las víctimas de delitos; la Directiva 2011/99/UE del Parlamento Europeo y del Consejo, de 13 de diciembre de 2011, sobre la Orden Europea de Protección) y el Reglamento (UE) núm. 606/2013 del Parlamento Europeo y del Consejo, de 12 de junio de 2013.

63 Sobre esta cuestión, Magdalena Martín Martínez, «Protección a las víctimas, violencia de género y cooperación judicial penal en la Unión Europea post-Lisboa», Revista de Derecho Comunitario Europeo n. ${ }^{\circ} 39$ (2011): 409-412.

${ }^{64}$ Incide en estos aspectos, Morgade Cortés, «La Orden Europea de Protección...»: 81-82.

65 Véase sobre esta cuestión, Protocolo común para la actuación sanitaria ante la Mutilación Genital Femenina (MGF), 2015, Ministerio de Sanidad, Servicios Sociales e Igualdad, Gobierno de España. Disponible en:

http://www.msssi.gob.es/organizacion/sns/planCalidadSNS/introProtocoloComun2015.htm. 
Europea de Protección (OEP) dejar ver diversas fallas en el sistema. La primera tiene que ver con las distintas cláusulas que contiene, que permiten en la práctica una importante fragmentación en la cooperación penal ${ }^{66}$. En segundo lugar, la OEP no busca la armonización entre los diversos Estados y su aplicación depende de decisiones judiciales previas por lo que protección se ve finalmente debilitada ${ }^{67}$. Pero, especialmente, las consecuencias más indeseables han sido la renuncia a la implementación de unos estándares normativos y a la delimitación de una estrategia integral en la lucha contra la violencia de género ${ }^{68}$. Una estrategia que atienda a los problemas sociales estructurales y que advierta en primer lugar de la necesidad de sensibilización a través del análisis, la reflexión, la formación, la educación, las políticas de integración y prevención, para lo cual es esencial visualizar el fenómeno en sí: definirlo con claridad.

Todas estas observaciones deben ser traídas al estudio y tratamiento de la MGF, teniendo en cuenta que además en esta última cuestión es preciso añadir las políticas de integración social de la migración. Este trabajo no puede ser escamoteado a través de respuestas parciales y ni mucho menos por reacciones sexistas y de resistencia al reconocimiento de la igualdad de derechos de las mujeres.

\section{Bibliografía}

Adam Muñoz, María Dolores. La mutilación genital femenina y sus posibles soluciones desde la perspectiva del Derecho Internacional Privado. Córdoba: Universidad de Córdoba, 2004.

Asua Batarrita, Adela. «Criminología y multiculturalismo. Medidas internacionales y propuestas de tratamiento jurídico para la erradicación de la mutilación genital femenina». Eguzkilore, n. ${ }^{\circ} 18$ (2004): 83-101.

Cueto Moreno, Cristina. «La Orden Europea de Protección. Su transposición en el Proyecto de Ley de reconocimiento mutuo de resoluciones penales en la Unión Europea». Revista de Derecho Constitucional Europeo n. ${ }^{\circ} 21$ (2014): 221-260.

Female genital mutilation in the European Union and Croatia. European Institute for Gender Equality, 2013. http://eige.europa.eu/sites/default/files/documents/ eige-report-fgm-in-the-eu-and-croatia.pdf

66 Y así lo destaca Martín Martínez, «Protección a las víctimas...», 436-437.

67 En este sentido Morgade Cortés, «La Orden Europea de Protección...»: 101; Cristina Cueto Moreno, «La Orden Europea de Protección. Su transposición en el Proyecto de Ley de reconocimiento mutuo de resoluciones penales en la Unión Europea», Revista de Derecho Constitucional Europeo n. ${ }^{\circ} 21$ (2014): 226-228.

${ }^{68}$ De esta opinión, Magaly Thill, «States'duty to prevent and eliminate violence againts women in the European Union», Revista Universitaria Europea n. ${ }^{\circ} 21$ (2014): 66-61. 
Fusaschi, Michela. «Modifications génitales féminines en Europe: raison humanitaire et universalismes ethnocentriques», Synergies Italie, n. ${ }^{\circ} 10$ (2014): pp. 95- 107.

Grande-Gascón, María Luisa; Ruiz-Seisdedos, Susana; Hernández-Padilla, María. «El abordaje social y político de la mutilación genital femenina». Portularia, Vol. XIII, n. ${ }^{\circ} 1$ (2013): 11-18.

Herrera Moreno, Myriam. «Multiculturalismo y tutela penal: a propósito de la problemática sobre la mutilación genital femenina». Lex Nova, n. ${ }^{\circ} 5$ (2002): 49-84.

Ismail, Asha, entrevista por María Gascón, publicada en «Página abierta» 236, enero-febrero de 2015, disponible en http://www.pensamientocritico.org/ ashism0215.htm.

Jiménez García, Francisco. «La mutilación genital femenina (MGF) y el principio de extraterritorialidad. A propósito de la sentencia de la Audiencia Nacional 9/2013 de 4 de abril de 2013». Revista española de Derecho Internacional, vol. LXV, núm.2 (2013): 349-356.

Johnsdotter, Sara. «The FGM Legislation Implemented: Experiences from Sweden», Cuadernos Electrónicos de Filosofía del Derecho, n. ${ }^{\circ} 17$ (2008): 1-12.

Kaplan Marcusán, Adriana y Martínez Bueno, Cristina (coords.). «Mutilación genital femenina: prevención y atención. Guía para profesionales», Associació Catalana de Llevadoras, Barcelona, 2004, http://www.aen.es/docs/guias_vg/ guia_mutilacion_genital.pdf.

Kaplan, Adriana; Torán, Pere; Bermúdez, Kira y Castany, María José. «Las mutilaciones genitales femeninas en España: posibilidades de prevención desde los ámbitos de la atención primaria de salud, la educación y los servicios sociales». Revista Migraciones, n. ${ }^{\circ} 19$ (2006): 189-217.

La Barbera, María Caterina. «Mujeres, migración y Derecho penal: el trato jurídico de la mutilación genital femenina». Sortuz. Oñati Joural of Emergent Sociolegal Studies, n. ${ }^{\circ}$ 4, 1 (2010): 34-67.

Leye, Els y Deblonde, Jessika «A comparative analysis of the different legal approaches towards female genital mutilation in the 15 EU Member States, and the respective judicial outcomes in Belgium, France, Spain, Sweden and the UK». ICRH Publications, n. ${ }^{\circ} 8$ (2004): 1-76.

Lucas, Bénédicte. «Aproximación antropológica a la práctica de la ablación o mutilación genital femenina». Cuadernos electrónicos de filosofía del Derecho 17 (2008): 1-13.

Martín Martínez, Magdalena. «Protección a las víctimas, violencia de género y cooperación judicial penal en la Unión Europea post-Lisboa». Revista de Derecho Comunitario Europeo n. ${ }^{\circ} 39$ (2011): 407-442.

Merchal Escalona, Nuria. «Mutilación genital femenina y violencia de género». En Actas del I Congreso Internacional sobre Migraciones en Andalucía, ed. por Francisco Javier García Castaño y Nina Kressova, 2179-2190. Granada: Instituto de Migraciones, 2011.

Merino i Sancho, Víctor M. «Derecho de asilo y género. ¿Ha evolucionado el derecho de asilo?». Cuadernos electrónicos de filosofía del Derecho 17 (2008): 1-10. 
Miguel Juan, Carmen. «La mutilación genital femenina, derecho de asilo en España y otras formas de protección internacional». Cuadernos Electrónicos de filosofía del Derecho, 17 (2008): 1-15.

Morgade Cortés, María. «La Orden Europea de Protección como instrumento tuitivo de las víctimas de la violencia de género». Cuaderno Electrónico de Estudios Jurídicos, n. 3 (2014): 79-112.

Organización Mundial para la Salud. «Mutilación genital femenina. Nota descriptiva», febrero, 2016. Entrada el 30 de noviembre de 2016, http://www. who.int/mediacentre/factsheets/fs241/es/

Ortega Sánchez, Isabel. «Narrativas periodísticas en torno a la ablación / mutilación genital femenina». En I Congreso Internacional de Comunicación y Género, editado por Juan Carlos Suárez Villegas, Irene H. Liberia Vayá, Belén Zurbano Berenguer, 1888-1904. Sevilla: Universidad de Sevilla, 2012.

Pastor, Daniel R. El poder penal internacional. Una aproximación jurídica crítica a los fundamentos del Estatuto de Roma. Barcelona: Atelier, 2006.

Pitch, Tamar. Un derecho para dos. La construcción jurídica de género, sexo y sexualidad. Madrid: Trotta, 2003.

Protocolo común para la actuación sanitaria ante la Mutilación Genital Femenina (MGF), 2015, Ministerio de Sanidad, Servicios Sociales e Igualdad, Gobierno de España. Disponible en: http://www.msssi.gob.es/organizacion/sns/ planCalidadSNS/introProtocoloComun2015.htm.

Rahman, Anika y Nahid Toubia. Female Genital Mutilation. A Practical Guide to Worldwide Laws and Policies. Londres: Zed Books, 2000.

Ropero Carrasco, Julia. «El Derecho Penal ante la Mutilación genital femenina». La Ley, n. ${ }^{\circ} 6$ (2001): 1393-1410.

Ropero Carrasco, Julia. «La mutilación genital femenina: una lesión de los derechos fundamentales de las niñas basada en razones de discriminación sexual», en Cursos de Derechos humanos de Donostia-San Sebastián, Vol. 4, editado por Juan Soroeta Liceras, 353-385. San Sebastián: Universidad del País Vasco, 2003.

Salamanca de Dueñas, Rocío. «Dossier II: Mutilación genital femenina: análisis criminológico y tratamiento jurídico penal». Quadernos de criminología: revista de criminología y ciencias forenses, n. ${ }^{\circ} 26$ (2014): 22-30.

Sanz Mulas, Nieves. «Diversidad cultural y política criminal: estrategias para la lucha contra la mutilación genital femenina en Europa (especial referencia al caso español)». Revista Española de Ciencia Penal y Criminología, 16-11 (2014) 11:1-11:49.

http://criminet.ugr.es/recpc/16/recpc16-11.pdf.

Serrano Maíllo, Alfonso. «El secuestro de la mutilación genital femenina: devolviendo la voz a sus protagonistas». Reseña de Beyond the dances. Voices of women on female genital mutilation, de $\mathrm{V}$. Barungi y $\mathrm{H}$. Twongyeirwe (Eds.). Kampala: FEMRITE, 2009, en Revista de Derecho UNED, Núm. 7, 2010.

Serrano Tárraga, María Dolores. «Violencia de género y extraterritorialidad de la ley penal. La persecución de la mutilación genital femenina», Revista de Derecho Uned, n. ${ }^{\circ} 11$ (2012): 867-888. 
Serrano Tárraga, María Dolores. «Diversidad cultural y ordenamiento jurídico penal: el delito de mutilación genital femenina en el Código Penal español», en Gestión de la diversidad cultural en las sociedades contemporáneas, ed. por María Teresa Regueiro García, Valencia, 2014.

SPF Santé publique, Sécurité de la Chaîre alimentaire et Environnement et GAMS Belgique. «Mutilatations Génitales Féminines: Guide à l'usage des professions concernées». Bruxelles (2011). Disponible en:

http://www .endfgm.eu/resources/tools-and-training-resources/mutilations-gnitalesfminines-guide-lusage-des-professions-concernes-2011/.

Thill, Magaly. «States'duty to prevent and eliminate violence againts women in the European Union». Revista Universitaria Europea n. ${ }^{\circ} 21$ (2014): 43-68.

Torres Fernández, María Elena. «La mutilación genital femenina: un delito culturalmente condicionado». Cuadernos Electrónicos de Filosofía del Derecho, n. ${ }^{\circ} 17$ (2008): 1-21.

UNICEF. «United Nations Children'Fund, Female Genital Mutilation/Cutting: A global concern», New York, 2016. Acceso el 30 de noviembre de 2016, https://www.unicef.org/media/files/FGMC_2016_brochure_final_UNICEF_ SPREAD.pdf.

United Nations High Commissioner for Refugees. «Mutilations génitales féminines et asile dans l'Union Européenne». New York, 2013. Acceso el 30 de noviembre de 2016.

http://www.refworld.org/cgi-bin/texis/vtx/rwmain/opendocpdf.pdf?reldoc= y\&docid=5163edf 14 .

Valero Heredia, Ana. «Derecho de asilo y mutilación genital femenina», Cuadernos de Derecho Público n. ${ }^{\circ} 30$ (2007): 79-93.

Vallejo Peña, Carmen. «Mutilación genital femenina: violencia de género con nuevas trabas para su persecución en España». Revista de Estudios Jurídicos Universidad de Jaén n. 14 (2014): 1-21.

\section{Sobre el autor}

Julia Ropero Carrasco es Profesora Titular de Derecho Penal, en la Universidad Rey Juan Carlos, Madrid, España. Es doctora en Derecho por la Universidad Complutense de Madrid (2000). Es autora de tres monografías y de numerosas colaboraciones en libros colectivos, así como de publicaciones en distintas revistas de carácter nacional e internacional. Las principales líneas de investigación sobre las que versan estas publicaciones son: terrorismo, delincuencia organizada, mujeres y menores y Derecho Penal, corrupción, codificación del Derecho Penal, armonización legislativa internacional y cooperación judicial.

Ha participado en distintos proyectos de investigación financiados, con especial interés en la delincuencia organizada y el terrorismo. Entre estos Proyectos, es Investigadora Principal de los siguientes: «La RES 2178 
de UN y su transposición a los Derecho Penales Nacionales: propuestas de equilibrio entra la seguridad y los derechos individuales» Ref. DER201677838-R, Entidad financiadora Ministerio de Economía y Competitividad (2016-2020); «Blanqueo de capitales y corrupción: acciones e interacciones desde el Derecho internacional y los sistemas nacionales para su efectiva erradicación», Ref. DER2013-41962-R, Entidad Financiadora Ministerio de Economía y Competitividad (2014-2017).

Entre las publicaciones más recientes se encuentran: «Aspectos críticos en la Mutilación Genital Femenina», en KAPLAN / NUÑO, «Guía Multisectorial de Formación Académicas sobre Mutilación Genital Femenina», Madrid, 2017, edit. Dykinson, 192 pp.; "Corruption in urban planning in Spain», Law Study, 2015, vol. XXVI, pp. 15-24; «El cuestionamiento de la legitimidad de las Cortes Penales Internacionales», en AZEREDO / FERNÁNDEZ, «Jurisdiçoes internacionais e evoluçao da ordem internacional», Universidad Católica Editora, Oporto, 2015, pp. 117-142; «Reformas penales y política criminal en la protección de la indemnidad sexual de los menores», Estudios Penales y Criminológicos, vol. 34, 2014, pp. 225-300; «Los delitos de pornografía infantil y ciber acoso tras las últimas reformas del Código Penal», en JORDÁ/DE PRIEGO, «La protección y seguridad de la persona en Internet. Aspectos sociales y jurídicos», Madrid, 2014, edit. Reus, pp. 123-157.

\section{About the author}

Julia Ropero Carrasco is Professor of Criminal Law at the Universidad Rey Juan Carlos, Madrid, Spain. She holds a doctorate in law from the Universidad Complutense de Madrid (2000). She is the author of three monographs and numerous collaborations in collective books, as well as publications in different magazines of national and international character. The main lines of research on these publications are: terrorism, organized crime, women and children and criminal law, corruption, codification of criminal law, international legislative harmonization and judicial cooperation.

He has participated in different funded research projects, with special interest in organized crime and terrorism. Among these Projects, she is Principal Investigator of the following: «UN RES 2178 and its transposition to National Criminal Laws: proposals for balance between security and individual rights» Ref. DER2016-77838-R, Funding Entity Ministry of Economy And Competitiveness (2016-2020); «Money Laundering and Corruption: Actions and Interactions from International Law and National Systems for Effective Eradication», Ref. DER2013-41962-R, Financing Entity Ministry of Economy and Competitiveness (2014-2017). 
Among the most recent publications are: «Critical Aspects in Female Genital Mutilation», in KAPLAN / NUÑO, «Multisectoral Guide to Academic Training on Female Genital Mutilation», Madrid, 2017, edit. Dykinson, 192 pp .; «Corruption in urban planning in Spain», Law Study, 2015, vol. XXVI, pp. 15-24; «The questioning of the legitimacy of the International Criminal Courts», in AZEREDO / FERNÁNDEZ, «International Jurisdictions and Evolution of the International Order», Universidad Católica Editora, Oporto, 2015, pp. 117-142; «Criminal reforms and criminal policy in the protection of the sexual indemnity of the minors», Criminal and Criminological Studies, vol. 34, 2014, pp. 225-300; «The crimes of child pornography and cyber harassment following the latest reforms of the Criminal Code,» in JORDÁ / DE PRIEGO, «The protection and security of the person on the Internet. Social and legal aspects», Madrid, 2014, edit. Reus, pp. 123-157. 


\section{Derechos de autor}

Los derechos de autor (para la distribución, comunicación pública, reproducción e inclusión en bases de datos de indexación y repositorios institucionales) de esta publicación (Cuadernos Europeos de Deusto, CED) pertenecen a la editorial Universidad de Deusto. El acceso al contenido digital de cualquier número de Cuadernos Europeos de Deusto es gratuito inmediatamente después de su publicación. Los trabajos podrán leerse, descargarse, copiar y difundir en cualquier medio sin fines comerciales y según lo previsto por la ley; sin la previa autorización de la Editorial (Universidad de Deusto) o el autor. Así mismo, los trabajos editados en CED pueden ser publicados con posterioridad en otros medios o revistas, siempre que el autor indique con claridad y en la primera nota a pie de página que el trabajo se publicó por primera vez en $C E D$, con indicación del número, año, páginas y DOI (si procede). Cualquier otro uso de su contenido en cualquier medio o formato, ahora conocido o desarrollado en el futuro, requiere el permiso previo por escrito del titular de los derechos de autor.

\section{Copyright}

Copyright (for distribution, public communication, reproduction and inclusion in indexation databases and institutional repositories) of this publication (Cuadernos Europeos de Deusto, CED) belongs to the publisher University of Deusto. Access to the digital content of any Issue of Cuadernos Europeos de Deusto is free upon its publication. The content can be read, downloaded, copied, and distributed freely in any medium only for non-commercial purposes and in accordance with any applicable copyright legislation, without prior permission from the copyright holder (University of Deusto) or the author. Thus, the content of $C E D$ can be subsequently published in other media or journals, as long as the author clearly indicates in the first footnote that the work was published in $C E D$ for the first time, indicating the Issue number, year, pages, and DOI (if applicable). Any other use of its content in any medium or format, now known or developed in the future, requires prior written permission of the copyright holder. 